Pure Appl. Chem., Vol. 75, Nos. 2-3, pp. 235-249, 2003.

(C) 2003 IUPAC

\title{
Progress in fumagillin synthesis*
}

\author{
W. Picoul, O. Bedel, A. Haudrechy, and Y. Langlois ${ }^{\ddagger}$ \\ Laboratoire de Synthèse des Substances Naturelles, Associé au CNRS, Université \\ de Paris-Sud, 91405 Orsay, France
}

\begin{abstract}
After a brief account of the syntheses previously described in literature, several approaches of the antiangiogenic sesquiterpene fumagillin are described. Particularly, a Claisen-Ireland ring-closing metathesis strategy allowed the stereoselective preparation of several advanced intermediates in the fumagillin synthesis.
\end{abstract}

Fumagillin 1, isolated in 1951 by Elbe and Hanson [1] from the microbial organism Aspergillus fumigatus, is representative of a class of sesquiterpenes such as ovalicin 2 [2] and FR 658143 [3], which display interesting biological activities. Fumagillin itself was first described as an antimicrobial agent, but more recently, Folkman and coworkers [4] discovered that this compound is a potent and selective inhibitor of angiogenesis. The same activity has been reported later for ovalicin 2 [5] which, as FR 65814 3, is also a potent immunosuppressor [3]. More recently, semisynthetic compound TNP-470 $4[6,7]$ showed a better therapeutic index than fumagillin $\mathbf{1}$. The recent discovery that methionine aminopeptidase II (MetAp-II) is selectively inhibited by fumagillin 1 [8] and the X-ray structure of the covalent complex between fumagillin 1 and MetAp-II [9] increases the interest of the synthesis of fumagillin 1 and of new fumagillin analogs [10,11].

After the pioneering synthesis of racemic fumagillin 1 by Corey in 1972 [12], this area of research remained dormant for 25 years. But in the past 5 years, 3 syntheses of (-)-fumagillin 1 or (-)-fumagillol 5, the direct precursor of fumagillin 1, [13-15] as well as two syntheses of racemic fumagillin 1/fumagillol $5[16,17]$ have been published.

From a biogenetic point of view, it has been demonstrated that fumagillin $\mathbf{1}$ and ovalicin $\mathbf{2}$ have as a common precursor $c i$-farnesyl pyrophosphate $[18,19]$. This biogenetic pathway has been recently reinforced by the discovery of a new metabolite $\mathbf{6}$ in the fermentation broth producing fumagillin 1 [20].

The structure of fumagillin 1 is characterized by the presence of six stereogenic centers, of a functionalized cis diol and of two epoxides. The spiro epoxide is easily the subject of nucleophilic attack and is essential [21] for the anti angiogenesis activity. Thus, the nucleophilic attack of histidine 231 of MetAp II gave rise to the formation of a covalent bond shown in the X-ray structure of the complex between 1 and MetAp II [9]. From a synthetic point of view, a possible precursor of fumagillin could be the terpene-like derivative 7 characterized by the presence of four double bonds. The selective functionalization of three of these double bonds can be considered as the main challenge in the synthesis of 1. Owing to the relative reactivity of these double bonds, the sequence of functionalization of each alkene is also fundamental.

\footnotetext{
* Pure Appl. Chem. 75, 141-419 (2003). An issue of reviews and research papers based on lectures presented at the $23^{\text {rd }}$ IUPAC International Symposium on the Chemistry of Natural Products, Florence, Italy, 28 July-2 August 2002 on the theme of natural products.

${ }^{\ddagger}$ Corresponding author
} 


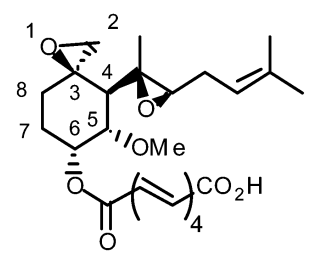

1: Fumagillin

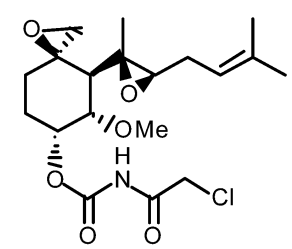

4: TNP-470

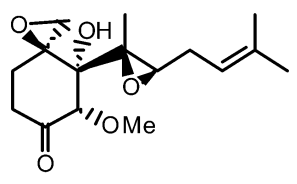

2: Ovalicin<smiles>CO[C@H]1[C@@H](O)[C@@H](O)CC[C@]12CO2</smiles>

5: Fumagillol<smiles>C=C1CCC=C[C@H]1/C(C)=C/CC=C(C)C</smiles><smiles>CO[C@H]1[C@@H](O)CC[C@@]2(CO2)[C@@H]1C(C)(C)[C@H]1O[C@H]1CC=C(C)C</smiles>

3: FR 65814<smiles>C=C1CC[C@H](OC(=O)/C=C/C(C)(C)C(=O)O)[C@@H]2[C@H](CC=C(C)C)O[C@H]12</smiles>

6

\section{Scheme 1}

A wide variety of strategies have been used in the previous syntheses. The Corey's synthesis [12] started with a Diels-Alder cycloaddition, which afforded in a few steps compound $\mathbf{8}$. A stereoselective epoxidation of the more reactive side chain-trisubstituted double bond was followed by the spiro epoxide formation with inversion of configuration. Dihydroxylation of the cyclohexene double bond affording compound 9 was followed by selective alkylation of the resulting diol. Introduction of the side chain-trisubstituted double bond completed the synthesis of ( \pm )-fumagillol 5 and of ( \pm )-fumagillin $\mathbf{1}$.

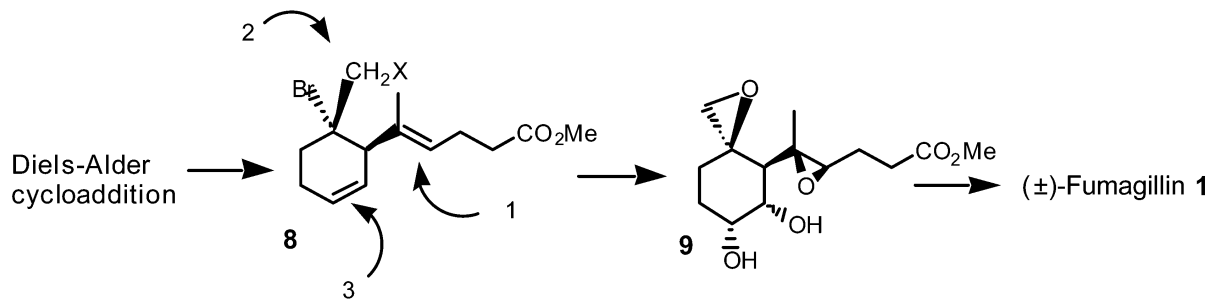

Scheme 2

The synthesis described by Kim [13] used D-glucose as starting material. This strategy allowed both the control of the configurations at C5 and C6 [22] and the differentiation between the two secondary alcohols. Compound $\mathbf{1 0}$ was obtained in 22 steps after a Claisen-Ireland rearrangement and a stereoselective ring closure allowing the control of the asymmetric center at C3 [22]. The spiro epoxide was then introduced after ester reduction. $m$-CPBA oxidation afforded selectively compound 11. The remaining trisubstituted double bond was obtained after ozonolysis and Wittig olefination. 


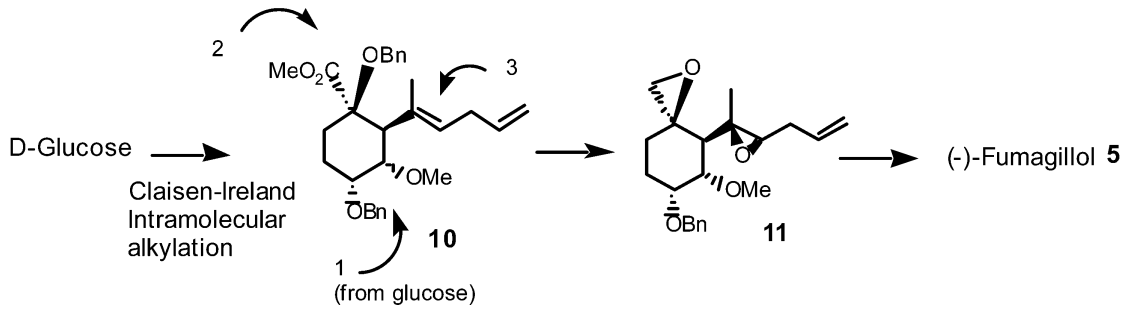

\section{Scheme 3}

The second enantioselective synthesis of fumagillin $\mathbf{1}$ [14] is characterized by a stereoselective insertion of carbene at one of the early steps. This reaction previously studied by Taber allowed the control of configuration at the future C3 [22]. Cyclohexenone derivative 14 was then obtained after ozonolysis of the cyclopentene intermediate and aldol condensation. The side chain was introduced by selective conjugate addition. Hydroxylation of the resulting silyl enol ether and reduction of the keto group afforded compound $\mathbf{1 5}$. The synthesis was then achieved after oxidative cleavage of diol in $\mathbf{1 5}$ and epoxide formation using a nucleophilic attack of the Corey's sulfoxonium ylide on the ketone intermediate. An inversion of configuration at C3 was thus performed at this stage. Side chain epoxidation was followed by oxidation of the side chain primary alcohol. Wittig olefination of the aldehyde intermediate completed the synthesis as in Kim's synthesis.

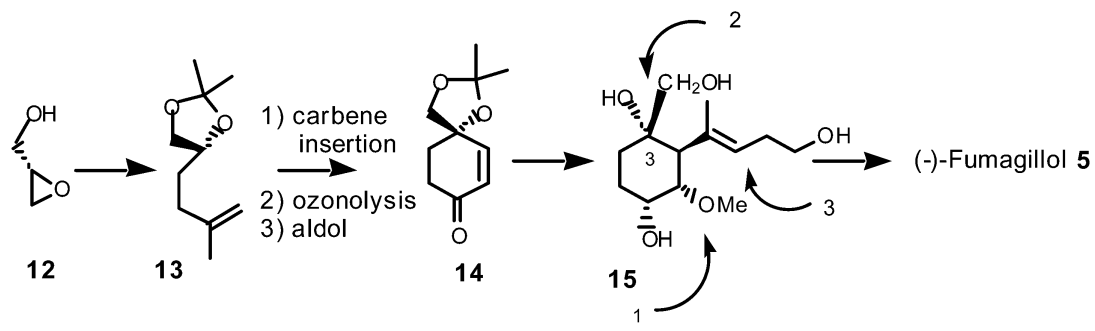

\section{Scheme 4}

Recently, Eustache's group described a third synthesis of (-)-fumagillin [15] using a completely different strategy. This original synthesis was characterized, from a retrosynthetic point of view, by an unexpected disconnection between C7 and C8 [22]. Ring-closing metathesis of the diene precursor 16 followed by hydrogenation of the resulting double bond afforded the cyclohexane core of fumagillin $\mathbf{1}$. The three asymmetric centers at C4, C5, and C6 in $\mathbf{1 6}$ were secured by an Evans aldol condensation between a suitable oxazolidinone and an $\alpha$-hydroxy aldehyde. As in Taber's synthesis, the spiro epoxide was obtained by the Corey's sulfoxonium ylide methodology. The synthesis was then completed by a side chain epoxidation, which was unexpectedly nonstereoselective.

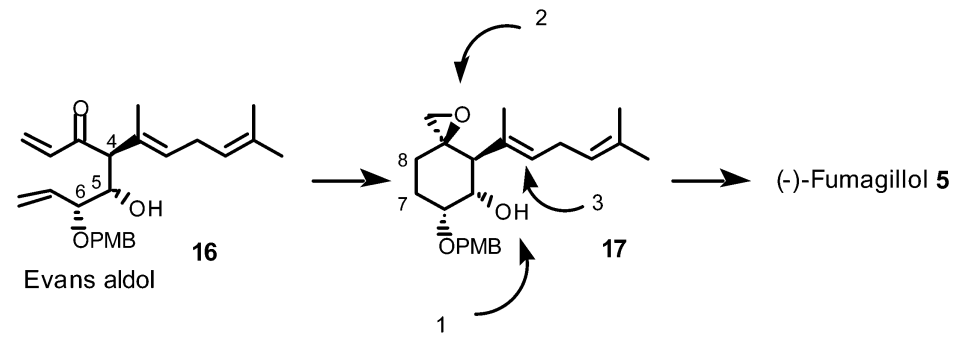

Scheme 5 
Sorensen's group described a concise synthesis of ( \pm )-fumagillol 5 [16]. Cyclohexadiene carboxaldehyde $\mathbf{1 8}$ was used as starting material. Regioselective dihydroxylation of $\mathbf{1 8}$ afforded the C5-C6 diol. Dienic side chain was then introduced by a conjugate addition on the resulting enal. A clever [3,3]sigmatropic rearrangement of a nitrone intermediate allowed the convenient functionalization and the control of configuration at $\mathrm{C} 3$ in compound 19. Spiro epoxide formation was achieved by an intramolecular nucleophilic substitution. Finally, selective side chain epoxydation of the homoallylic double bond was performed under Sharpless conditions.

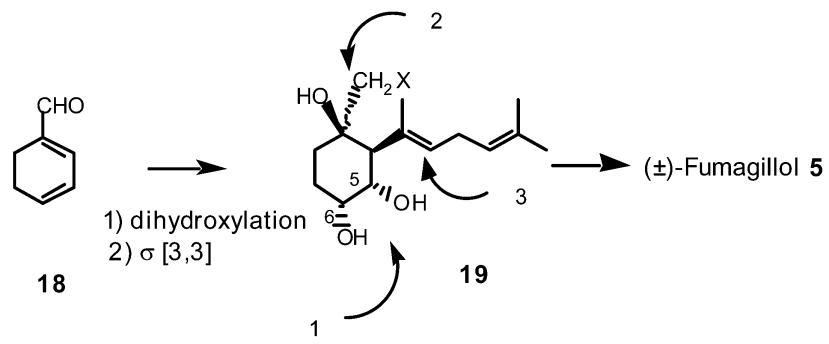

Scheme 6

More recently, another expeditious synthesis of ( \pm )-fumagillol 5 has been described by Simpkins [17]. Palladium-catalyzed 1,4 hydroxylation of cyclohexadiene afforded a cis diol. Selective epoxydation followed by protection of alcohols as $p$-methoxybenzyl (PMB) ethers gave the meso compound 20. Cyanocuprate-mediated nucleophilic attack on epoxide allowed introduction of side chain and controls the relative configurations at C4, C5, and C6. In that case, the Corey's sulfoxonium ylide methodology gave rise to an undesired elimination followed by cyclopropanation. The use of chloromethyllithium overcame this problem and afforded the expected chlorhydrine. Basic treatment of the chlorhydrine intermediate gave rise to spiro epoxide derivative 21. Known steps were then used to achieve the synthesis of $( \pm)$-fumagillol 5 .

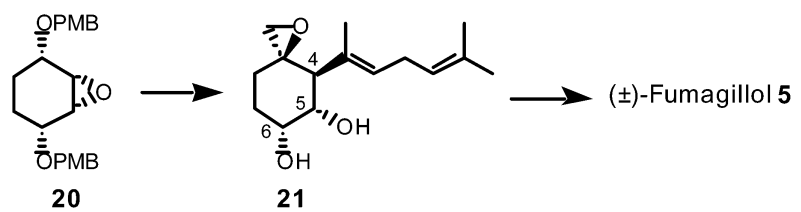

Scheme 7

Our initial plan for the synthesis of fumagillin $\mathbf{1}$ involved in a key step, a Claisen-Ireland rearrangement of the enolate $\mathbf{2 3}$ derived from 6-alkylidene lactone $\mathbf{2 2}$ [23,24]. In order to control the relative configuration between $\mathrm{C} 3$ and $\mathrm{C} 4$, a $Z$-double bond has to be introduced in $\mathbf{2 2}$. This requirement imposes severe constraints in the boat-like transition state in $\mathbf{2 3}$, which prevents the rearrangement to take place. In fact, we were not able under various conditions to realize this transformation $[25,26]$. However, olefin ring-closing metathesis [27] offered a nice alternative to our initial scheme. An allylic ester such as $\mathbf{2 4}$ could rearrange through the chair-like transition state $\mathbf{2 5}$, giving rise to compound $\mathbf{2 6}$ in which configurations at $\mathrm{C} 3$ and $\mathrm{C} 4$ are simultaneously controlled. Ring-closure metathesis could lead to the target cyclohexene derivative 27 . 


\section{Claisen-Ireland}

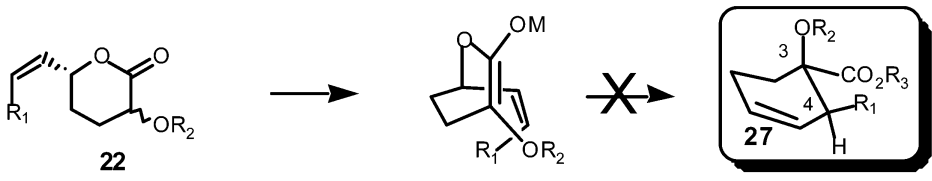

23 boat like TS

Claisen-Ireland - metathesis

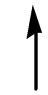<smiles>[R]C=C[C@H](C)OC(=O)C(CCC=C)O[R20]</smiles>

24

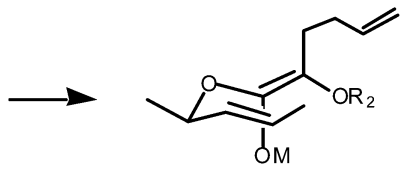

25 chair like TS<smiles>[R]C([R20])C([R20])(CCC=C)C([R])C=CC</smiles>

26

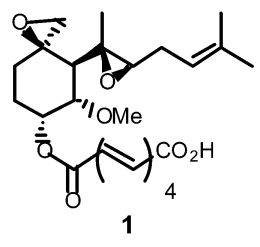

Scheme 8

Accordingly, the retrosynthetic scheme following this new strategy is illustrated in Scheme 9.

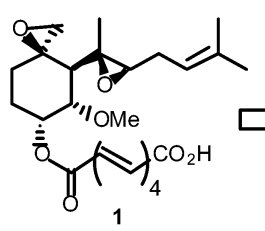

1

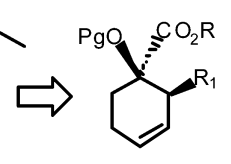

Olefin metathesis

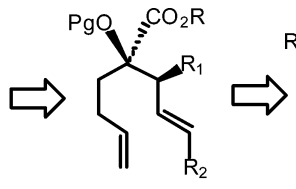

Claisen-Ireland rearrangement<smiles>[R7]C=C[C@H]([R])O</smiles><smiles>[C]1C=C1</smiles><smiles>C=CCCC(OC(=O)O)C(=O)O</smiles>

Scheme 9

The target allylic alcohol $\mathbf{2 9}$ was prepared in six steps following a known procedure [28] from ethyl lactate 28. $\alpha$-Hydroxyester 30 was obtained in two steps [29]. Protection of the alcohol followed

\section{Allylic ester preparation}
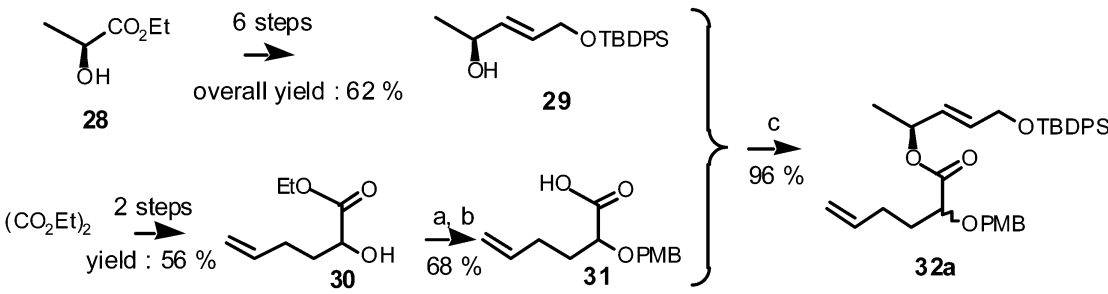

a) $\mathrm{Cl}_{3} \mathrm{CC}$ (OPMB)NH, 4 equiv., $\mathrm{TfOH}$, cat., $\mathrm{CH}_{2} \mathrm{Cl}_{2}, 0^{\circ} \mathrm{C}, 20 \mathrm{~h}$.

b) $\mathrm{KOH}, \mathrm{MeOH}, \mathrm{H}_{2} \mathrm{O}$. c) DCC, 1.2 equiv., DMAP, 0.1 equiv., $1 \mathrm{~h}$.

\section{Mitsunobu reaction :}

\section{Scheme 10}

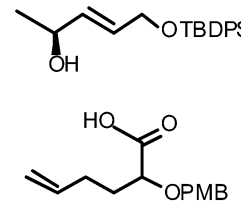

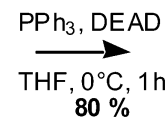

$80 \%$

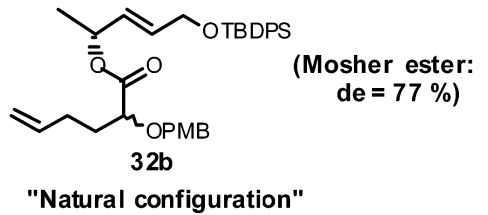

"Natural configuration" 
by saponification gave rise to acid derivative 31. Ester 32a was then obtained in high yield. However, in this ester, which has been used in a model study, the chiral center has the reverse absolute configuration for (-)-fumagillin synthesis. For this reason, the pseudo enantiomeric ester 32b was prepared by a Mitsunobu condensation. The enantioselectivity of this nucleophilic substitution was measured after saponification and reesterification, affording the corresponding Mosher ester.

Classical reaction conditions for the Claisen-Ireland rearrangement with ester $\mathbf{3 2}$ afforded a mixture of isomers 35 and 36 in 27/73 ratio after diazomethane esterification [30]. Addition of hexamethylphosphoramide (HMPA) reversed the selectivity, but the reaction remained poorly diastereoselective. Finally, a good result was obtained by changing both the base and the solvent. With potassium bis(trimethylsilyl)amide (KHMDS) in toluene, a ratio 35/36 up to $95 / 5$ was observed. Compounds 35 and 36 could be obtained theoretically through four different transition states. We believe that, with a PMB protecting group that reinforces the basicity of oxygene lone pairs, the chelated $Z$-enolates $\mathbf{3 3}$ and $\mathbf{3 4}$ are more likely than $E$-enolates $\mathbf{3 7}$ and $\mathbf{3 8}$. But the influence of the solvent and of the cation remains unclear for the moment. Change in the protecting group could give further information concerning the stereoselective outcome of this rearrangement.

Claisen-Ireland rearrangement

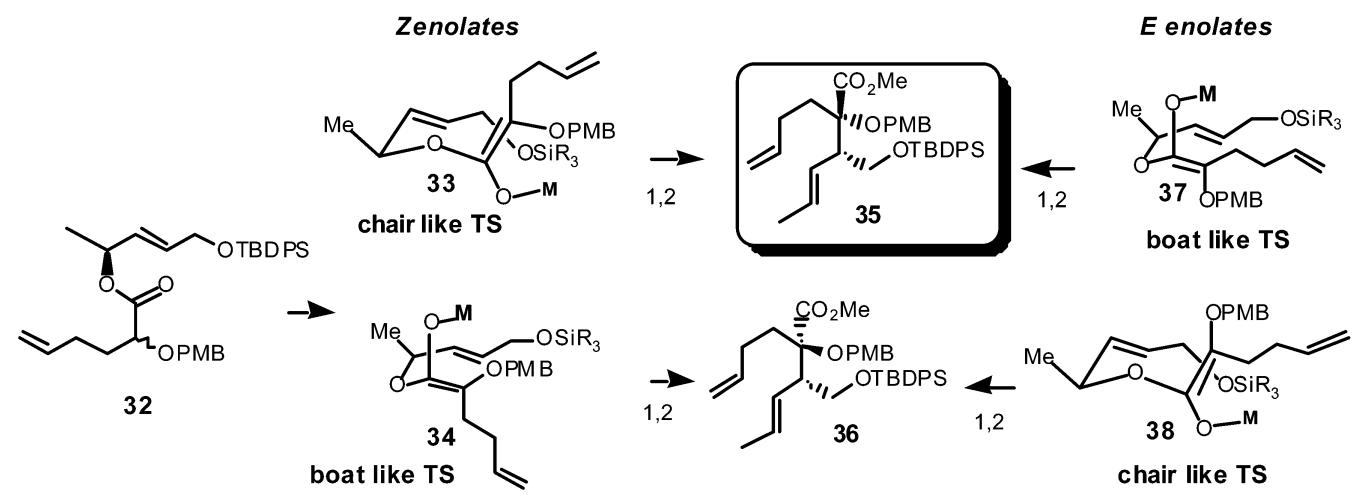

1) LDA, THF, $\left.-78^{\circ} \mathrm{C}, 30 \mathrm{~min}, \mathrm{ClSiMe}_{3} \mathrm{RT}, 90 \mathrm{~min} .2\right) \mathrm{CH}_{\mathbf{2}} \mathbf{N}_{\mathbf{2}}, \mathrm{Et}_{2} \mathrm{O}$ :

$35: 36=27 / 73$, yield $: 52 \%$.

1) LDA, THF-HMPA, $-78^{\circ} \mathrm{C}, 30 \mathrm{~min}$., $\left.\mathrm{CISiMe}_{3}, \mathrm{RT}, 90 \mathrm{~min} .2\right) \mathrm{CH}_{2} \mathbf{N}_{2}$, $\mathrm{Et}_{2} \mathrm{O}: \mathbf{3 5 : 3 6}=\mathbf{5 8 / 4 2}$.

1) KHMDS, PhMe, $-78^{\circ} \mathrm{C}, 30$ min., $\mathrm{ClSiMe}_{3}, \mathrm{RT}, 90 \mathrm{~min}$. 2) $\mathrm{CH}_{2} \mathbf{N}_{2}$ $\mathrm{Et}_{2} \mathrm{O}: \mathbf{3 5 : 3 6}>\mathbf{9 5 / 5}$, yield : $90 \%$.

\section{Scheme 11}

Having secured the control of asymmetric centers in ester 35, the ring-closing metathesis with the classical Grubbs catalyst was next examined. This reaction afforded nearly quantitatively the cyclohexene derivative 39. Reduction of the ester group followed by esterification of the resulting primary alcohol gave rise to compound $\mathbf{4 0}$ in $96 \%$ overall yield from 35. A diastereoselective dihydroxylation and protection of the diol afforded compound 41. Finally deprotection of the primary alcohol and oxydation with tetrapropylammonium perruthenate (TPAP) furnished aldehyde $\mathbf{4 2}$ with an overall yield of $54 \%$ from ester 35 [31]. 
Olefin metathesis and dihydroxylation

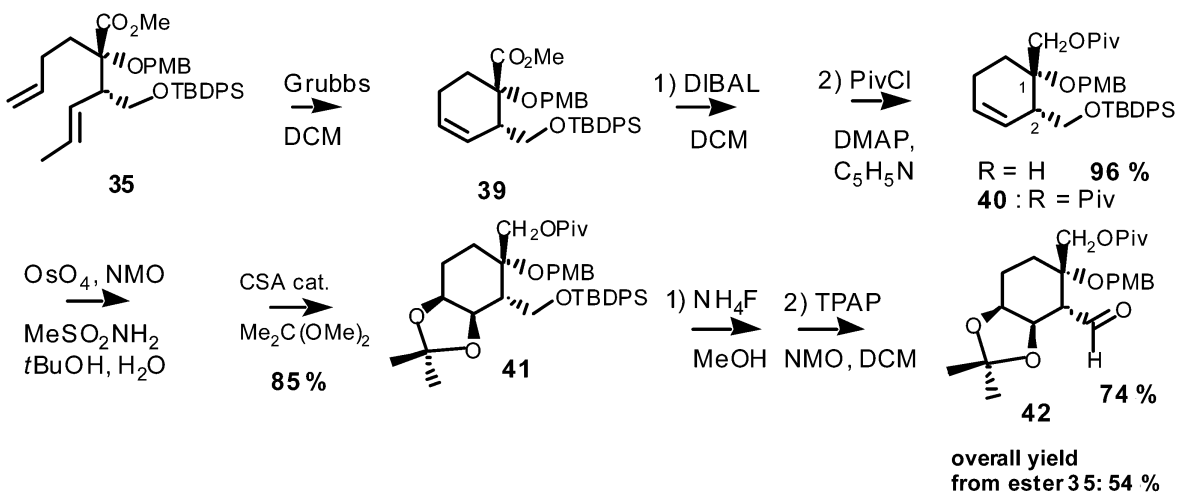

\section{Scheme 12}

With aldehyde 42 in hand, it was originally planned to introduce in one step, following the Negishi methodology [32], the dienic side chain after conversion of the aldehyde group in an alkyne. However, to our disappointment, using the method described by Ohira and Bestmann [33], even under mild reaction conditions, led to fast elimination of the OPMB group affording $\alpha, \beta$-unsaturated aldehyde 43 rather than the anticipated alkyne derivative $\mathbf{4 4}$.

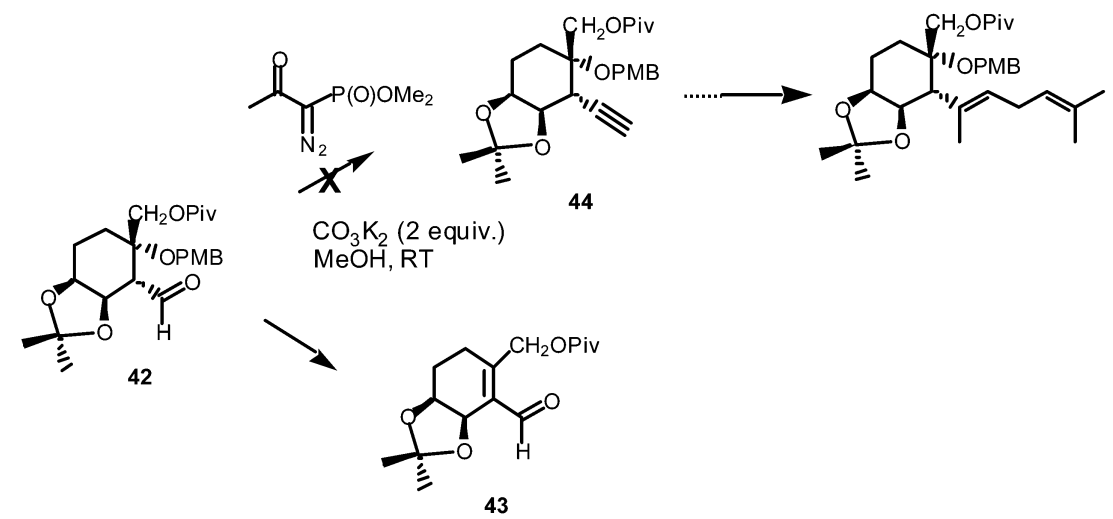

Scheme 13

This undesired side reaction was overcome by a six-step sequence as shown in Scheme 14. Aldehyde 42 was transformed in methyl ketone $\mathbf{4 5}$ in two steps. Nucleophilic attack of the vinyl Grignard reagent afforded in turn the allylic alcohol 46. Oxidative rearrangement furnished the $\alpha, \beta$-unsaturated aldehyde 47 . Reduction of aldehyde and substitution with chlorine gave rise to the chloro derivative $\mathbf{4 8}$ in $50 \%$ overall yield from aldehyde $\mathbf{4 2}$. Stille-type coupling afforded finally compound 49 in $32 \%$ unoptimized yield. Compound 49 was structurally close to compound 50, previously described by Sorensen [16]. However, considering that compound 49 was obtained by a rather lengthy sequence, albeit in good overall yield, and that a chemical correlation between 49 and 50 required additional steps, we decided at this stage to study a more convergent approach. 

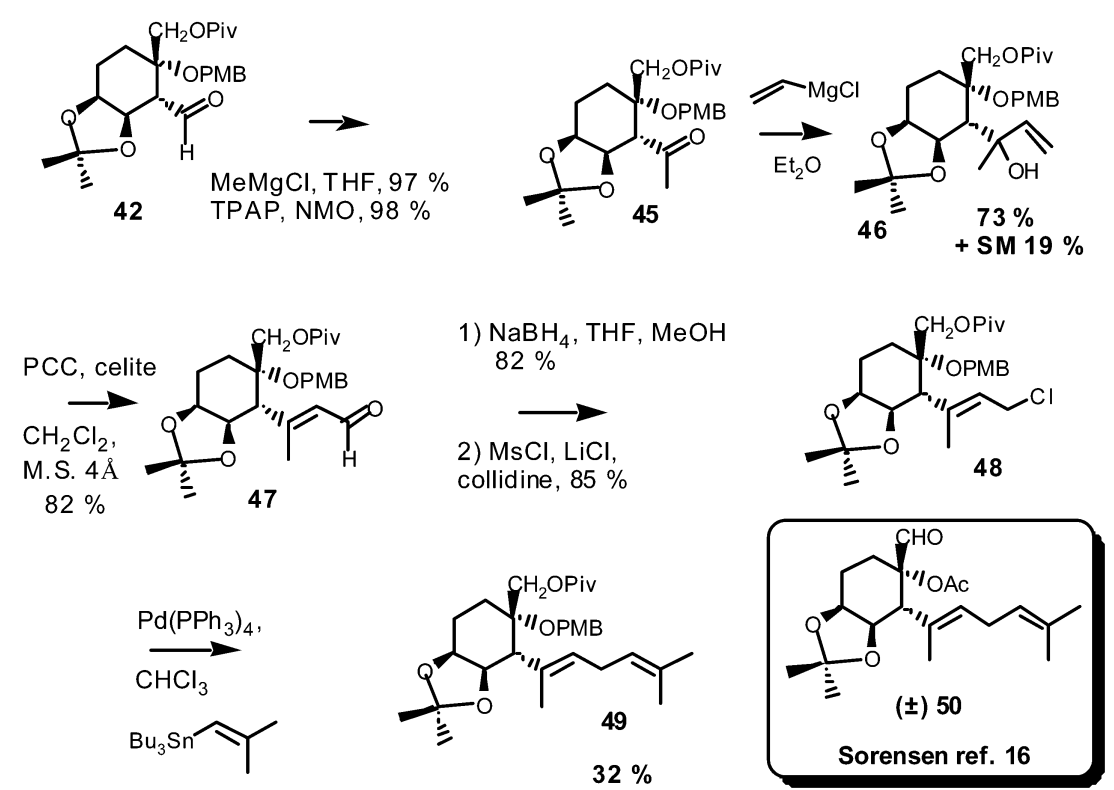

Scheme 14

The Claisen-Ireland metathesis strategy allowed a versatile introduction of substituents on the fumagillin 1 side chain. Introduction of one of the two trisubstituted double bonds on the side chain before rearrangement seemed to be attractive in light of our precedent results. This novel approach is illustrated in the retrosynthetic Scheme 15.

A more convergent approach :

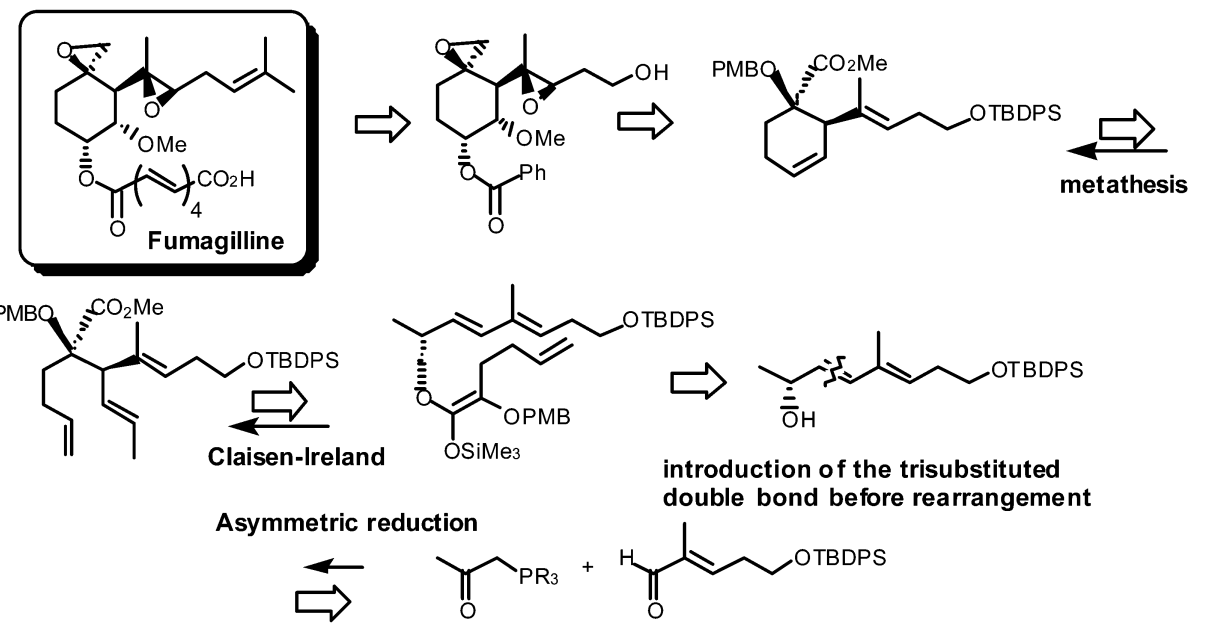

\section{Scheme 15}

Monoprotected diol 51 was oxidized, and the resulting aldehyde 52 after Wittig-Horner olefination afforded the dienic ketone 53. This compound was reduced using Corey's oxazaborolidine methodology [34]. Diene allylic alcohol $\mathbf{5 4}$ was obtained with a diastereoselectivity of 5.8 to 1 . Classical esterification furnished ester $\mathbf{5 5}$ [35]. Claisen-Ireland rearrangement under the previous conditions afforded compound $\mathbf{5 6}$ in good yield and excellent stereoselectivity. 
2nd approach: Claisen-Ireland rearrangement of dienic allylic ester
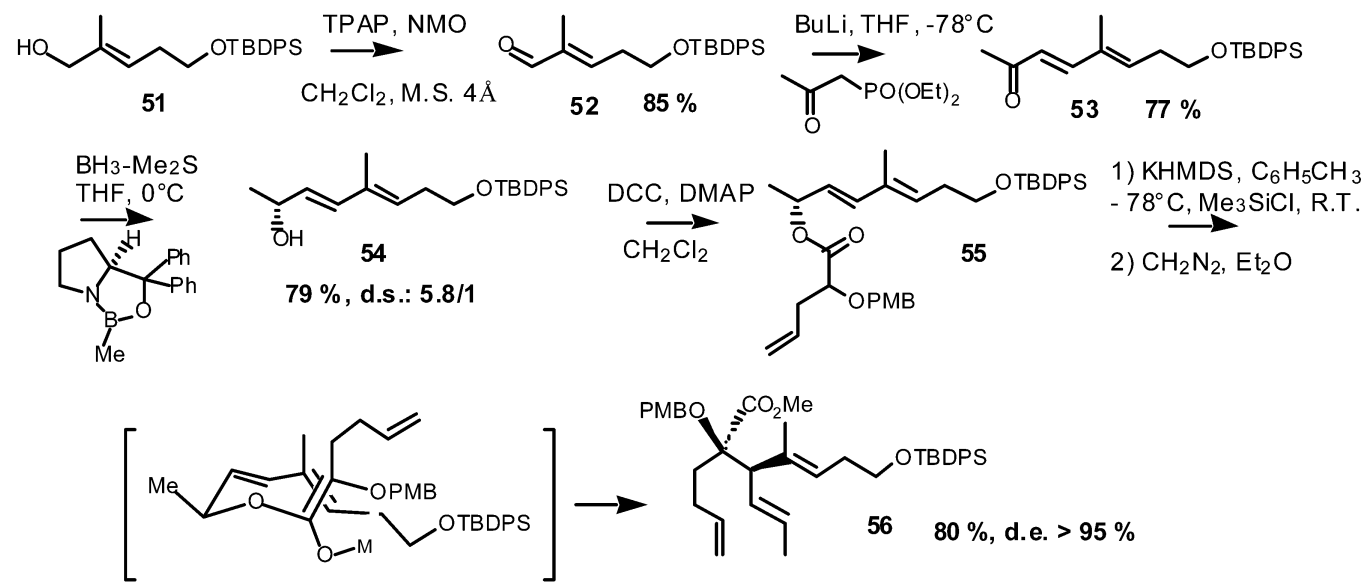

Scheme 16

As previously, alkene ring-closing metathesis proceeded smoothly to afford compound $\mathbf{5 7}$ in nearly quantitative yield. Selective oxidation of the trisubstituted double bond in $\mathbf{5 7}$ to give epoxide derivative 58 required particular conditions: 5 equiv of $m$-CPBA, 10 equiv of $\mathrm{NaHCO}_{3}, 0{ }^{\circ} \mathrm{C}, 3 \mathrm{~min}$ in $\mathrm{CH}_{2} \mathrm{Cl}_{2}$. Ester group in $\mathbf{5 8}$ was in turn reduced with diisobutyl aluminum hydride (DIBAH) giving rise to compound 59. However, at this stage, we were not able to deprotect the PMB ether with classical reagents such as ceric ammonium sulfate or dichlorodicyano- $p$-benzoquinone (DDQ) without epoxide opening with participation of the primary alcohol. We then decided to examine the formation of the spiro epoxide before side chain epoxidation. Thus, compound $\mathbf{5 7}$ was reduced with DIBAH, and the resulting primary alcohol $\mathbf{6 1}$ was deprotected without any problem but in modest yield. After mesylation of the primary alcohol and basic treatment, the spiro epoxide $\mathbf{6 2}$ was isolated.

2nd approach: metathesis, epoxidations<smiles>[R6]OCC/C=C(\COC)[C@@H](/C=C/C)[C@](C)(CCC=C)CCCCC</smiles>

1) side chain epoxidation:

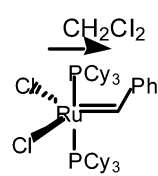<smiles>CO/C(=C\CCO[14C](=O)OC)[C@H]1C=C[B-]CC1</smiles>

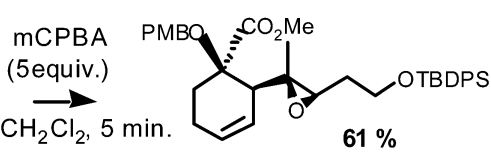

58 (S.M. : $18 \%$ )

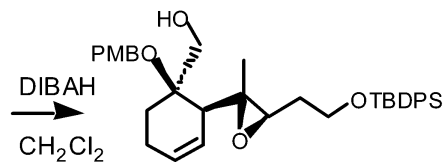

$5980 \%$

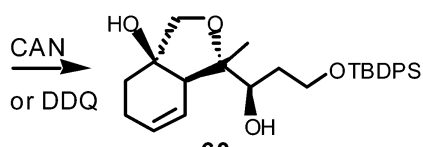

60

2) oxirane formation:
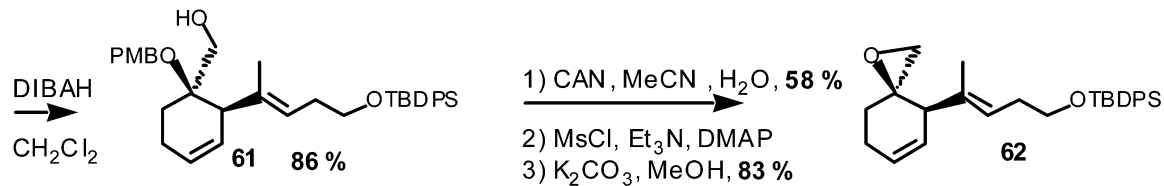

Scheme 17 
In contrast with the selectivity observed in epoxidation of compound $\mathbf{5 7}$, the same reaction on compound 62 was totally unselective and afforded a mixture of diastereomeric epoxides 63 and 64 . The same behavior was observed with compounds 65-70. This result was unexpected in regard of the preceding reactions in this series. Dihydroxylation of epoxide 63 afforded cleanly the corresponding diol 71. Dibenzoylation followed by the deprotection of primary alcohol gave rise to compound $\mathbf{7 2}$. Comparison between $\mathbf{7 2}$ and compound 73, previously described by Taber [14], allowed the attribution of configurations for the side chain epoxide in $\mathbf{7 2}$.

2nd approach: side chain epoxidation<smiles>C/C(=C\CCO[SnH3])[C@H]1C=CCCC12CC2</smiles>

62

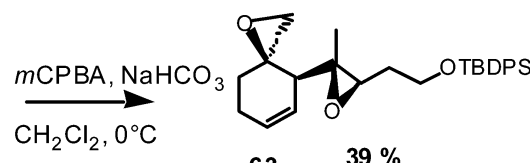

63

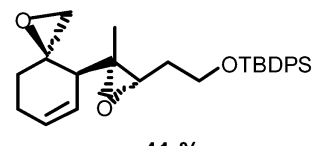

64

$41 \%$

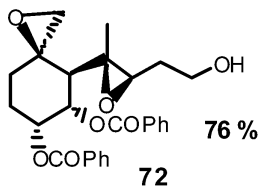

Possible correlation

$?$
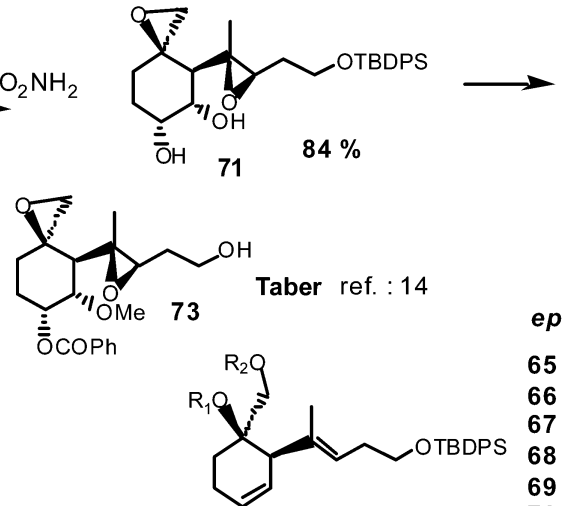

epoxidations without selectivity

$65: \mathrm{R}_{1}=\mathrm{H} ; \mathrm{R}_{2}=\mathrm{Ms}$

$66: \mathrm{R}_{1}=\mathrm{H} ; \mathrm{R}_{2}=\mathrm{SO}_{2}$ Mesityl

$67: R_{1}=T M S ; R_{2}=S_{2}$ Mesityl

68: $\mathrm{R}_{1}=\mathrm{PMB} ; \mathrm{R}_{2}=\mathrm{SO}_{2}$ Mesityl

$69: R_{1}=P M B ; R_{2}=C O\left(C_{3}\right)(O M e) P h$

$70: R_{1}+R_{2}=C(M e)_{2}$

Scheme 18

The lack of selectivity for the side chain epoxidation was a major drawback in this approach. For this reason, it was attractive to examine the possible introduction of the epoxide functional group before the Claisen-Ireland rearrangement. To this goal, allylic alcohol $\mathbf{5 1}$ was submitted to a highly selective Sharpless epoxidation. Oxidation of the alcohol epoxide intermediate was followed by a Wittig reaction, which gave rise to compound 74. Luche reduction gave a mixture of diasteromeric alcohols $\mathbf{7 5}$,

3rd approach: introduction of side chain epoxide before rearrangement
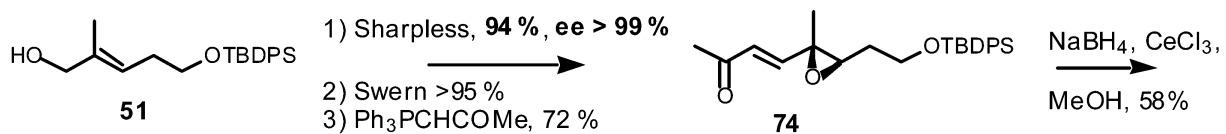

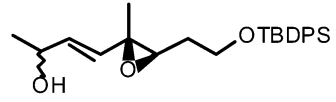

75 (unstable)

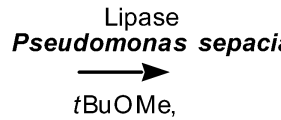

YAc

Scheme 19

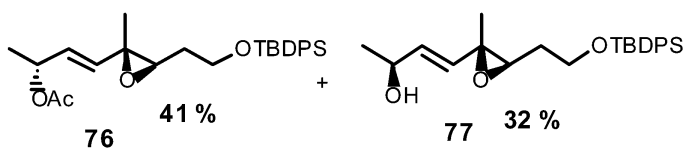

Esters of (absolute configuration):<smiles>CO[C@@H](C(=O)O)c1ccccc1</smiles> 
which were differentiated by enzymatic kinetic resolution affording ester $\mathbf{7 6}$ and pseudo enantiomeric alcohol 77 in good yield and selectivity. Absolute configurations were established by NMR after saponification of $\mathbf{7 6}$ and reesterification with acid $\mathbf{7 8}$.

After saponification of ester $\mathbf{7 6}$ and reesterification of the alcohol intermediate with acid 31, the resulting allylic ester $\mathbf{7 9}$ was submitted to the Claisen-Ireland reaction conditions. The rearranged compound 80 was obtained with nearly complete stereoselectivity and in acceptable yield. However, all compounds in this series were rather unstable, and the sequence of reactions has to be performed without interruption. This is an obvious difficulty for large-scale preparation.

\section{3rd approach: Claisen-Ireland rearrangement on allylic ester epoxide}

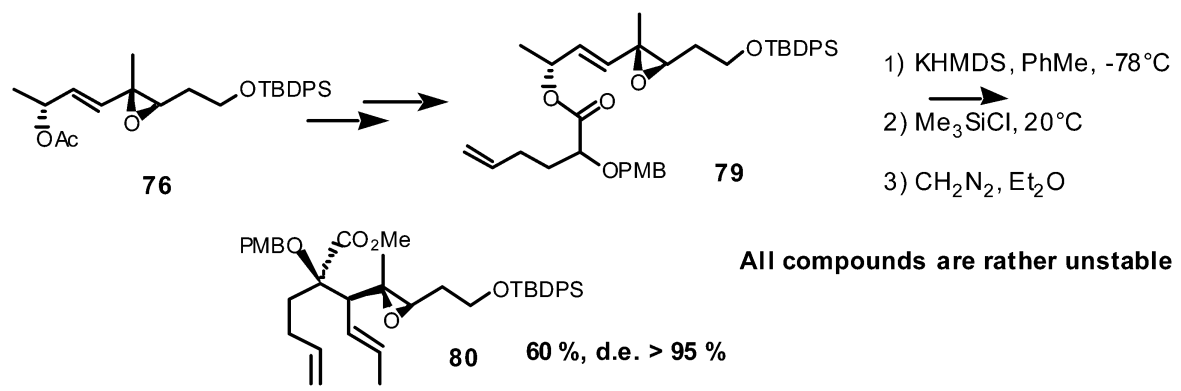

Scheme 20

In the meantime, the side reaction observed during PMB ether cleavage (Scheme 17) led us to imagine an internal protection of the side chain-trisubstituted double bond, which could allow selective dihydroxylation of the cyclohexene moiety. Regeneration of the side chain double bond in homo allylic position with the hydroxy group at C5, could be followed by a stereoselective Sharpless epoxidation as illustrated in the retrosynthetic Scheme 21.

4th approach - Internal protection of the trisubstituted double bond by lactonisation retrosynthetic analysis:
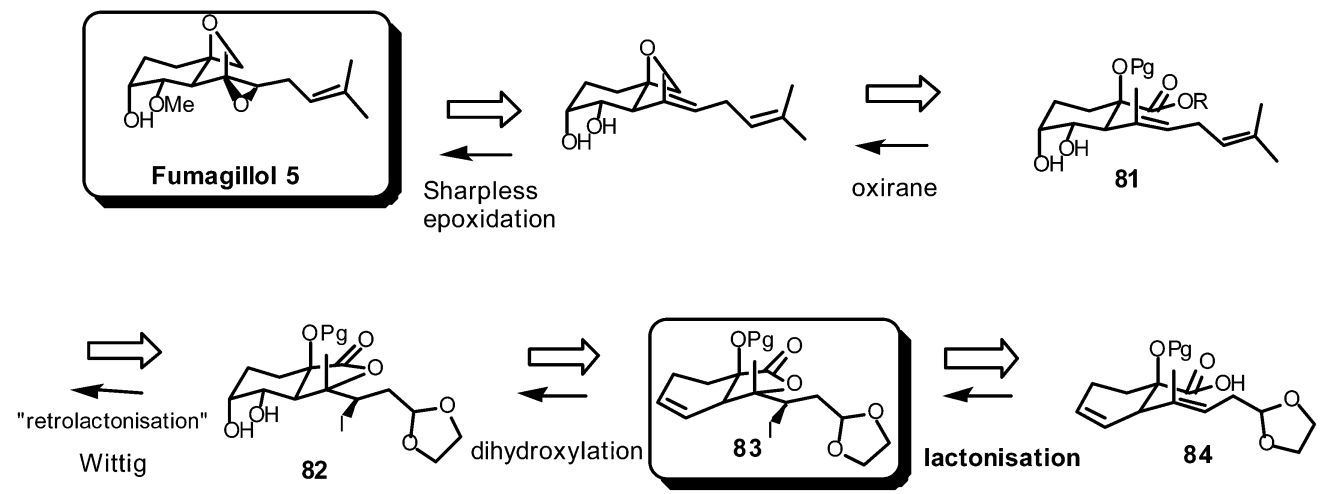

Scheme 21

In order to circumvent the poor selectivity of ketone $\mathbf{5 3}$ reduction by oxazaborolidine method (Scheme 16), another pathway using once again the chiral pool was examined. Accordingly, diisopropylidene mannitol $\mathbf{8 5}$ was submitted to an oxidative cleavage [36] and the resulting aldehyde afforded, after Wittig-Horner olefination, ketone $\mathbf{8 6}$ in high yield. Three possibilities were next tested 
for the selective introduction of the trisubstituted double bond. However, neither Julia-Johnson rearrangement [37] nor tertiary allylic alcohol rearrangement were selective enough, and the purification of the major $E$-isomer was problematic. Here again, Wittig reaction gave good results and afforded with good yield and selectivity compound $\mathbf{9 1}$. A careful hydrolysis of the isopropylidene-protecting group afforded diene $\mathbf{9 2}$ with a stereoselectivity up to $95 \%$. Protection of the primary alcohol furnished compound 93.

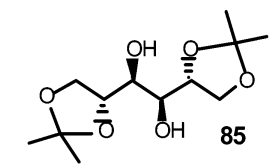

diisopropylidène mannitol

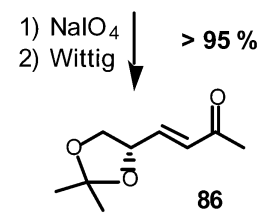

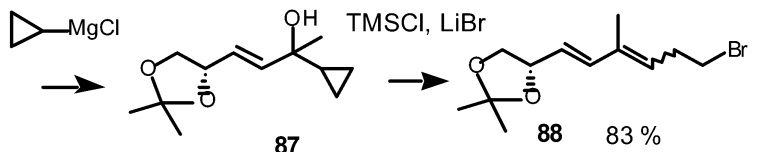

87

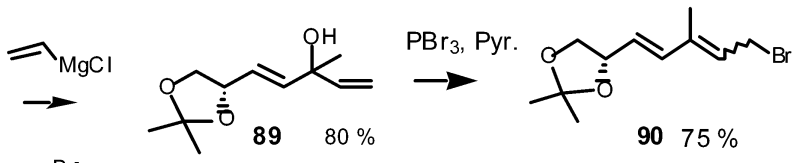

$\mathrm{Br}^{-}$<smiles>Pc1ccccc1</smiles>

BuLi<smiles>CCCOC1COC(C)(C)O1</smiles>

$9188 \%$<smiles>CC(C=CC(O)CO)=CCC1OCCC1=O</smiles>

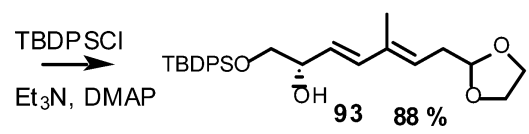

$E / Z>95$

Scheme 22

As previously, esterification of alcohol 93 with acid $\mathbf{3 1}$ was followed by Claisen-Ireland rearrangement, which afforded compound $\mathbf{9 6}$ in good yield and excellent stereoselectivity. Starting from

\section{Rearrangement - Metathesis}<smiles>CC(C=C[C@@H](O)CO[18O])=CCC1OCCO1</smiles>

93<smiles>C=CCCC(OCC)C(=O)OC(C)(C)C(N)=O</smiles>

31<smiles>CCCCC(=O)O[C@@H](/C=C/C(C)=C/CC1OCCO1)CCC(=O)O[Mg]</smiles>

94

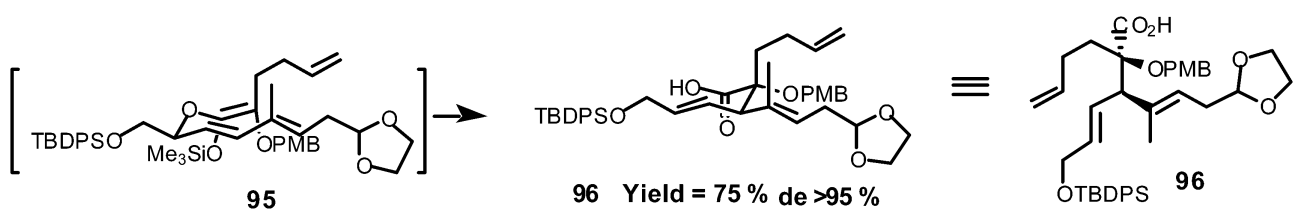

95

96 Yield $=75 \%$ de $>95 \%$

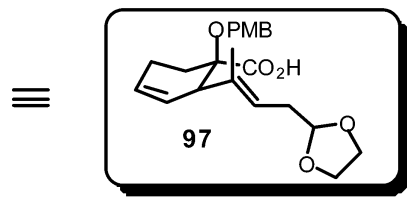

Scheme 23 
the unprotected acid 96, the ring-closing metathesis was carried out with the classical Grubbs catalyst and furnished cyclohexene derivative $\mathbf{9 7}$ in nearly quantitative yield.

Iodo lactonization on compound $\mathbf{9 7}$ was induced with $N$-iodo succinimide and afforded in high yield lactone 98. Under classical conditions, dihydroxylation furnished diol 99. This compound was in turn protected as a benzylidene derivative 100. Zinc-mediated retrolactonization gave rise, after diazomethane esterification, to compound 101. This compound was obtained in $28 \%$ overall yield for 11 steps from diisopropylidene mannitol $\mathbf{8 5}$. Selective deprotection of one of the alcohols in the benzylidene protecting group is under study as well as the remaining steps to complete the total synthesis of fumagillol 5 .
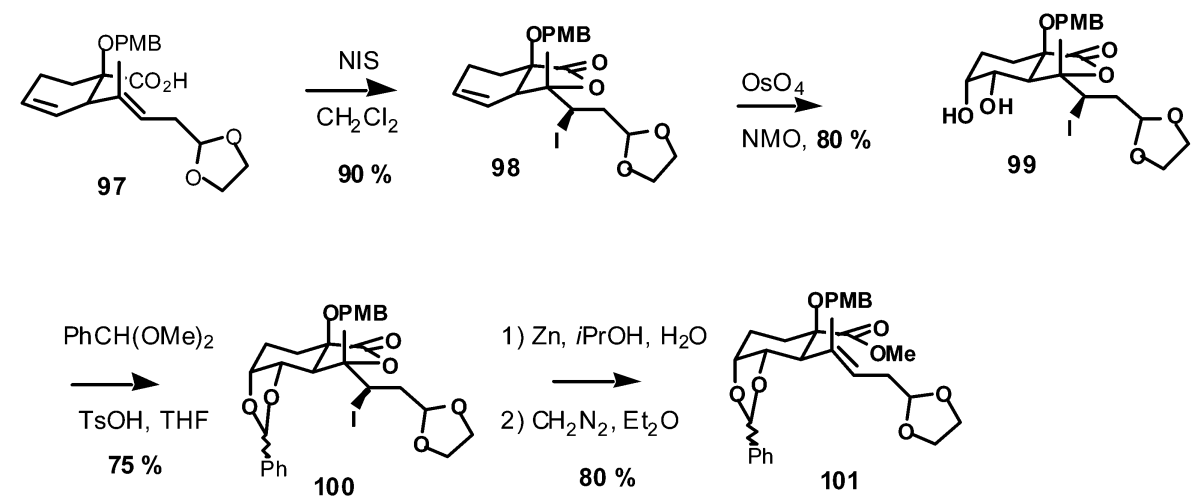

Scheme 24

A possible correlation with tetrol $\mathbf{1 0 4}$ described by Sorensen [16] is also in progress. Iodo lactone 99 was treated with zinc in isopropanol as described earlier (Scheme 24) and esterified. Acetylation furnished the diacetate 102. To achieve this correlation, several steps are still in progress: dioxolane deprotection, Wittig olefination, DIBAH reduction of the three-ester groups in 103, and DDQ deprotection of the tertiary alcohol.
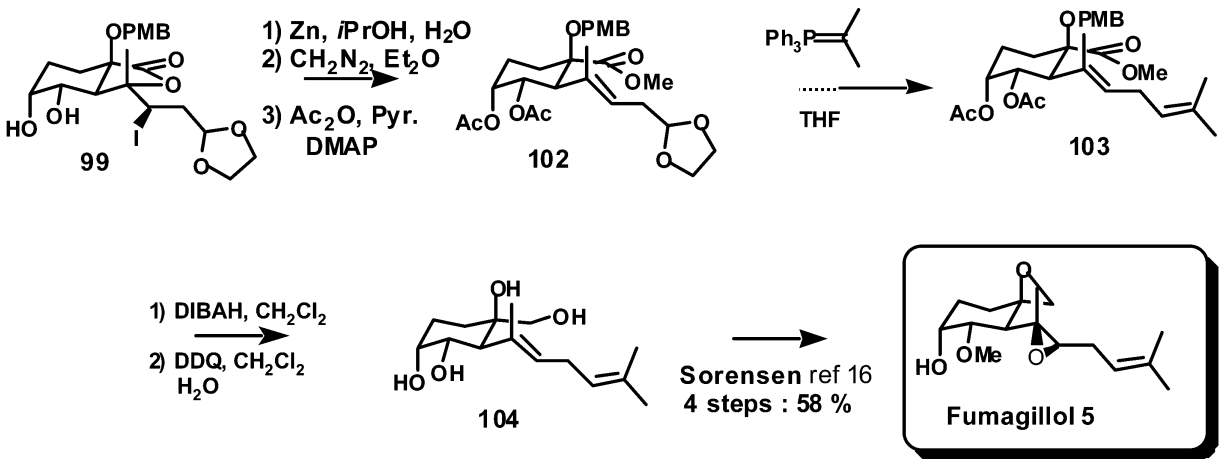

Scheme 25

In summary, we have demonstrated that a Claisen-Ireland ring-closing metathesis strategy gave rise to advanced intermediates in the fumagillin 1 synthesis. The high yield obtained in the fourth approach led us to be confident of the completion of this synthesis. 


\section{ACKNOWLEDGMENTS}

The Ministry of Education is acknowledged for grants to W.P. and O.B., and the University of ParisSud and CNRS for financial supports.

\section{REFERENCES AND NOTES}

1. T. E. Elbe and F. R. Hanson. Antibiot. Chemother. 1, 54 (1951).

2. H. P. Sigg and H. P. Weber. Helv. Chim. Acta 51, 1395 (1968).

3. H. Hatanaka, T. Kino, M. Hashimoto, Y. Tsurumi, A. Kuroda, H. Tanaka, T. Goto, M. Okuhara. J. Antibiot. 41, 999 (1988).

4. D. Ingber, T. Fujita, S. Kishimoto, K. Sudo, T. Kanamaru, H. Brem, J. Folkman. Nature 348, 555 (1990).

5. E. J. Corey, A. Guzman-Perez, M. C. Noe. J. Am. Chem. Soc. 116, 12109 (1994) and references therein.

6. B. J. Dezube. J. Clin. Onc. 16, 1444 (1998).

7. (a) For other TNP-470 derivatives, see: S. Marui, T. Yamamoto, K. Sudo, H. Akimoto, S. Kishimoto. Chem. Pharm. Bull. 43, 588 (1995); (b) N. Sin, L. Meng, M. Q. W. Wang, J. J. Wen, W. G. Bornmann, C. M. Crews. Proc. Natl. Acad. Sci. USA 94, 6099 (1997); (c) E. C. Griffith, Z. Su, S. Niwayama, C. A. Ramsey, Y. H. Chang, J. O. Liu. Proc. Natl. Acad. Sci. USA 95, 15183 (1998); (d) C. K. Han, S. K. Ahn, N. S. Choi, R. K. Hong, S. K. Moon, H. K. Chun, S. J. Lee, J. W. Kim, C. I. Hong, D. Kim, J. H. Yoon, K. T. No. Bioorg. Med. Chem. 10, 39 (2000).

8. W. T. Lowter, D. A. McMillen, A. M. Orville, B. W. Matthews. Proc. Natl. Acad. USA 95, 12153 (1998).

9. S. Liu, J. Widom, C. W. Kemp, C. M. Crews, J. Clardy. Science 282, 1324 (1998).

10. For a review concerning low-molecular-weight compound inhibitors of angiogenesis, see: A. Giannis and F. Rubsam. Angew. Chem., Int. Ed. Engl. 36, 588 (1997).

11. For a recent synthesis of oxa-fumagillin analog, see: J. E. Baldwin, P. G. Bulger, R. Marquez. Tetrahedron 58, 5442 (2002).

12. E. J. Corey and B. B. Snider. J. Am. Chem. Soc. 94, 2549 (1972).

13. D. Kim, S. K. Ahn, H. Bae, W. J. Choi, H. S. Kim. Tretrahedron Lett. 38, 4437 (1997).

14. D. F. Taber, T. E. Christos, A. L. Rheingold, I. A. Guzei. J. Am. Chem. Soc. 121, 5589 (1999).

15. J.-G. Boiteau, P. Van de Weghe, J. Eustache. Org. Lett. 3, 2737 (2001).

16. D. A. Vosburg, S. Veiler, E. J. Sorensen. Angew. Chem., Int. Ed. 38, 971 (1999).

17. M. Hutchings, D. Moffat, N. S. Simpkins. Synlett 661 (2001).

18. A. J. Birch and S. F. Hussain. J. Chem. Soc. 1473 (1969).

19. D. E. Cane and D. B. Mc Ilwaine. Tetrahedron Lett. 28, 6545 (1987).

20. J. Halasz, B. Podanyi, L. Vasvari-Debreczy, A. Szabo, F. Hadju, Z. Böcskei, J. Hegedus-Vajda, A. Gyorbiro, I. Hermecz. Tetrahedron 56, 10081 (2000).

21. However, in some fumagillin analogs, which displayed in vivo antitumor activity, the spiro epoxide is transformed into a hydroxy methylenesulfonium derivative, see ref. $7 \mathrm{a}$.

22. For clarity, the fumagillin numbering has systematically been used.

23. For a model reaction, see: G. Büchi and J. E. Powell Jr. J. Am. Chem. Soc. 92, 3126 (1970).

24. For recent accounts of Claisen-Ireland rearrangements, see: (a) Y. Chai, S-p. Hong, H. A. Lindsay, C. McFarland, M. C. McIntosh. Tetrahedron 58, 2905 (2002); (b) D. Enders, M. Knopp, R. Schiffers. Tetrahedron: Asymmetry 7, 1847 (1996); (c) J. S. Panek, S. Schaus, C. E. Masse. Chemtracts: Org. Chem. 8, 238 (1995). 
25. Alternatively, it was possible to prepare an enantiomeric lactone of $\mathbf{2 2}$ with an $E$-double bond on side chain. Rearrangement of this lactone could give rise to a diastereomer of $\mathbf{2 7}$ with natural configuration at $\mathrm{C} 4$ and unnatural at $\mathrm{C} 3$. Inversion of configuration at $\mathrm{C} 3$ as in previous syntheses could then be realized. However, the lengthy preparation of lactone 22 [26] was a major drawback for the use of this alternative.

26. W. Picoul. Ph.D. thesis, Université de Paris-Sud, Orsay, 18 January 2001.

27. For reviews on olefin metathesis, see: (a) A. Fürstner. Angew. Chem., Int. Ed. 39, 3012 (2000); (b) R. H. Grubbs and C. Sukbok. Tetrahedron 54, 4413 (1998).

28. Y. Ichikawa, K. Tsuboi, M. Isobe. J. Chem. Soc., Perkin Trans. 12791 (1994).

29. J. A. Macritchie, A. Silcock, C. L. Willis. Tetrahedron: Asymmetry 8, 3895 (1997).

30. Configurations in $\mathbf{3 5}$ and $\mathbf{3 6}$ were determined by nuclear Overhauser effect experiments after reduction of the ester group, esterification of the resulting primary alcohol with pivaloyl chloride, and protection of the tertiary alcohol as diphenyl tertbutylsilyl ether. The enantiomeric purity was measured, after reduction of the esters groups in $\mathbf{3 5}$ and $\mathbf{3 6}$ with $\mathrm{LiAlD}_{4}$ by the method described by Courtieu et al., see: [26] and I. Canet, A. Meddour, A. Lowenstein, J. M. Péchiné, J. Courtieu. J. Am. Chem. Soc. 117, 6520 (1995).

31. W. Picoul, R. Urchegui, A. Haudrechy, Y. Langlois. Tetrahedron Lett. 40, 4797 (1999).

32. E. I. Negishi, D. E. Van Horn, T. Yoshida. J. Am. Chem. Soc. 107, 6639 (1985).

33. (a) S. Ohira. Synth. Commun. 19, 561 (1989); (b) S. Müller, B. Liepold, G. J. Roth, H. J. Bestmann. Synlett 521 (1996).

34. E. J. Corey, R. K. Bakshi, S. Shibata, C. P. Cheng, V. K. Singh. J. Am. Chem. Soc. 52, 5406 (1987).

35. Minor diastereomers were eliminated at this stage during ester purification.

36. (a) H. Ronneberg, G. Borch, R. Buchecker, N. Arpin, S. Liaaen-Jensen. Phytochemistry 21, 2087 (1982); (b) S. Ohira, T. Ida, M. Moritani, T. Hasegawa. J. Chem. Soc., Perkin Trans. 1293 (1998).

37. (a) M. Julia, S. Julia, R. Guégan. Bull. Soc. Chim. Fr. 1072 (1960); (b) S. Brady, M. A. Ilton, W. S. Johnson. J. Am. Chem. Soc. 90, 2882 (1968). 